\title{
Da aurora d̀ meia-noite e a questão da intermedialidade no expressionismo
}

From Morn to Midnight and the Question of Intermediality in Expressionism

Michael Korfmann ${ }^{1}$

\begin{abstract}
This article aims to reassess the question of intermediality in expressionism in regard to From morn to midnight. Written between 1912 and 1915 by Georg Kaiser and published in 1916, the text has been staged in many theatres from 1917 on. In 1920 director Karl Heinz Martin undertook its transposition into film. The first part of this investigation examines the text in relation to theatrical traditions and possible adaptations of cinematic techniques. It then analyzes the scenic aspects of its staging in the context of the new visuality of expressionist theatre while the third part takes a closer look at the cinematic adaption in the context of the long lasting debate on expressionist cinema.
\end{abstract}

Key-words: From Morn to Midnight; Georg Kaiser; Karl Heinz Martin; Expressionism

Resumo: O presente artigo objetiva reavaliar a questão intermedial do expressionismo referente à Da aurora à meia-noite, obra destacada de Georg Kaiser. O texto, escrito entre 1912 e 1915, e publicado em 1916, foi encenado em inúmeros teatros a partir de 1917. Em 1920, o diretor Karl Heinz Martin realizou sua transposição para o medium fílmico. A primeira parte do presente estudo analisa a forma textual de Da aurora à meia-noite entre tradição teatral e possíveis adaptações de técnicas cinematográficas. A seguir, investiga-se o aspecto visual de sua encenação no âmbito da nova visualidade expressionista no teatro, enquanto que a terceira parte se ocupa do filme Da aurora à meia-noite no contexto da permanente discussão sobre o chamado cinema expressionista

Palavras-chave: Da aurora à meia-noite - Georg Kaiser - Karl Heinz Martin - expressionismo

\footnotetext{
${ }^{1}$ Professor Associado do Instituo de Letras da Universidade Federal do Rio Grande do Sul (UFRGS). Email: michael.korfmann@ufrgs.br
} 


\section{Introdução}

O objetivo do presente artigo é investigar configurações e adaptações mediais de $D a$ aurora à meia-noite (KAISER 2010), uma das mais destacadas obras do expressionismo alemão. Escrito entre 1912 e 1915 por Georg Kaiser e publicado em 1916, o texto foi encenado em inúmeros teatros a partir de 1917. Em 1918, o diretor Karl Heinz Martin apresentou sua versão no teatro Thalia em Hamburgo e, dois anos depois, o próprio Martin realizou a transposição de Da aurora à meia-noite para o medium fílmico. Perdida durante décadas e apenas restaurada em 2009, a película tornou-se disponível, desde maio de 2010, em DVD editado pelo Deutsche Filmmuseum München.

Esse exemplo concreto de uma obra artística, transposta para diferentes formas mediais, insere-se numa discussão mais ampla sobre o caráter intermedial do expressionismo como um todo. Uma das marcas destacadas da arte alemã, tanto na própria Alemanha bem como no exterior, que historicamente se desenvolveu entre 1905 (fundação da Brücke em Dresden) e 1925 (exposição Neue Sachlichkeit em Mannheim), o expressionismo, com suas revistas próprias, editoras, clubes, cabarés e cafés, sempre foi visto como algo mais do que um simples estilo literário ou uma forma visual específica. Em sua lendária publicação de 1926, Rudolf KURTZ tende a concebê-lo como "consequência histórica"2 (2007: 10), "uma espiritualidade geral" (2007: 15) e o compreende como "visão de mundo" (2007: 10), ou seja, descreve-o dentro de uma concepção abrangente, representativa para toda uma época histórica. Ja a exposição bem sucedida de 2010/11 (Gesamtkunstwerk Expressionismus) o situa mais explicitamente dentro do campo artístico, ao constatar sua "interdisciplinaridade destacada" (BEIL/DiLlmanN 2010: 14).

De um lado, muitos representantes do expressionismo tinham talento duplo. Ernst Barlach, Oskar Kokoschka, Wassilj Kandinsky e Alfred Kubin produziram não só importantes obras visuais, mas também textos literários. De outro, notam-se, além desses dados biográficos, influências mútuas mais abrangentes entre as diversas manifestações artísticas como: literatura, pintura, música, dança, arquitetura e cinema. Consequentemente, a exposição acima mencionada recorre ao conceito do

\footnotetext{
${ }^{2}$ As traduções de fontes em língua alemã foram feitas pelo autor.
} 
Korfmann, M. - Da aurora à meia-noite

Gesamtkunstwerk da tradição romântica e wagneriana como definição adequada e título de sua mostra, uma denominação já feita por Hugo Ball em 1914 (BALME 1988: 249). Esperava-se da interação da luz, da cor, da palavra, da música e do gesto a intensificação da expressão e do efeito artístico. Isso corresponde ao ideal de um artista capaz de se expressar com criatividade universal em todas as formas de arte, concepção formulada pelo expressionista e dadaísta Kurt SCHWITTERS, de modo a "borrar as fronteiras entre as formas de arte" (1965: 15).

A arte e a literatura do expressionismo alemão se desenvolveram, portanto, paralelas uma à outra e em mútua dependência. E foram sustentadas, também em parte, pelas mesmas pessoas. A própria história do conceito reforça essa interação. Na Alemanha, o conceito "expressionismo" surgiu em 1911 e se expandiu rapidamente. Chamava-se, inicialmente, expressionista a mais recente arte da França, os fauvistas e os cubistas, quadros, entre outros, de George Braque, André Dérain, Raoul Dufy, Albert Marquet, Pablo Picasso e Maurice de Vlaminck. Pouco tempo depois, transferiu-se a denominação também para as obras dos artistas da Brücke, fundada em 1905, em Dresden, e para o grupo Der Blaue Reiter, fundado em 1911, em Munique. Em julho de 1911, Kurt Hiller estendeu esse conceito para a literatura recente da época. Chamou de expressionistas os membros do Neue Club, fundado em março de 1909 em Berlim, e do Neopathetische Cabaret que surgiu em 1911 a partir daquele. Lá, Ernst Blass, Jakob van Hoddis e Georg Heym liam seus poemas. Esse clube literário e esse cabaré são tradicionalmente considerados o "embrião da literatura expressionista na Alemanha" (ANZ 1995: 260).

Nesse contexto, traçado aqui de forma resumida, Da aurora à meia-noite parece ser, por razões diversas, uma obra artística quase exemplar para as discussões sobre o expressionismo e seu caráter intermedial. Trata-se, em primeiro lugar, de uma obra transposta e encenada em diversas formas mediais. Em segundo, porque, como obra expressionista, faz parte de uma vertente artística concebida frequentemente na tradição do Gesamtkunstwerk e, assim, representante de um movimento visto por muitos teóricos sob o critério de sua múltipla configuração medial. Além dos dois níveis analíticos citados aqui - a obra e suas diversas transposições, bem como um período históricoartístico com forte marcação intermedial - encontramos ainda reflexões mais 
Korfmann, M. - Da aurora à meia-noite

abrangentes, que avaliam Da aurora à meia-noite como obra sintomática para toda a cultura da época. Como exemplo mais recente de tais visões, podemos citar Cynthia WALK que, em seu artigo "Cross-Media Exchange in Weimar Culture: Von morgens bis mitternachts" (2007: 178), apresenta Da aurora à meia-noite como objeto de um "exemplary case study of intermediality in Weimar culture".

Frente ao fato de que tanto a peça de Georg Kaiser está agora disponível em português (cf. KAISER 2010), bem como a versão fílmica restaurada de Karl Heinz Martin em DVD, pretendemos neste artigo reavaliar tais constatações nas três partes deste trabalho. A primeira se ocupa com sua forma textual entre tradição teatral e possíveis adaptações de técnicas cinematográficas. Da aurora à meia-noite foi escrita numa fase histórica, quando o cinema deixava de ser uma mera curiosidade técnica de feiras populares para tornar-se um verdadeiro "concorrente com a literatura reinante" (KAES 1978: 2), conhecido como a lendária Kinodebatte. Portanto, é necessário perguntar se a progressiva ascensão do novo medium, inicialmente encontrando a resistência de uma elite burguesa que, educada tradicionalmente no teatro e na literatura, ainda via, no filme, uma forma de contracultura que buscava equiparar-se à cultura oficial, realmente resultou cada vez mais em uma praxe intermedial, ultrapassando tais fronteiras culturais e discursivas.

A segunda parte investigará a visualidade da encenação teatral expressionista. Da aurora à meia-noite estreou em 1917 em Munique. Karl Heinz Martin, que dirigiria três anos mais tarde a versão fílmica, encenou-a em 1918 no teatro Thalia em Hamburgo. Em 1919, fundou em Berlim Die Tribüne, um dos teatros mais inovadores da cena expressionista. $\mathrm{O}$ teatro foi inaugurado com duas peças de Walter Hasenclever, Der Retter (O salvador) e Die Entscheidung (A decisão) e inovou, sobretudo, em nível visual. Eliminou-se a caixa do palco, substituindo-a por uma plataforma um pouco acima do nível da plateia e renunciando completamente a um cenário. Logo depois, apresentou Die Wandlung (A transformação), de Ernst Toller, onde Martin e seu cenarista, Robert Neppach, traçaram em linhas bizarras, reduzidas e elementares sobre espaços de papelão, os contornos dos cenários, causando grande impacto com suas “imagens gráficas apenas insinuadas e o poder sugestivo das telas” (RÜHLE 1967: 159). Essa encenação tornou Martin uma celebridade e uma marca do teatro expressionista. 
Korfmann, M. - Da aurora à meia-noite

Em fevereiro de 1920, Max Reinhardt o contratou, tanto como diretor de seu renomado Großes Schauspielhaus, bem como gerente geral de todos seus teatros em Berlim. Assim, apresentamos nessa parte as reflexões teóricas e a práxis teatral de Martin no período em questão, a fim de entender sua concepção referente à visualização do texto dramático de Kaiser e as possíveis consequências para sua transposição fílmica, investigando, assim, um elo conceitual entre o medium teatral e fílmico.

Consequentemente, a terceira etapa deste artigo se ocupa do filme Da aurora à meia-noite, no contexto da permanente discussão sobre o chamado cinema expressionista. Martin colaborou para seu filme com representantes de duas media: do lado teatral, destaca-se a colaboração de Robert Neppach, o cenarista responsável por sua famosa encenação de Die Wandlung (A transformação), de Ernst Toller, no teatro Tribüne em Berlim. Entre os atores, havia Ernst Deutsch, como destacado representante de atuação expressionista no teatro, mas também ator em diversos filmes desde 1916, e Erna Morena, atriz com longa carreira cinematográfica. A gravação e o lado fílmicotécnico ficaram sob a responsabilidade de Carl Hoffmann, um diretor de fotografia com grande experiência no cinema. Diferente do lendário O Gabinete do Dr. Caligari, do mesmo ano de 1920, que, apesar das distorções visuais do cenário pintado, mantém a ilusão do espaço tridimensional para sua narrativa, baseada em motivos da literatura romântico-gótica do século XIX, Da aurora à meia-noite parece optar por um caminho mais radical. Dominam, no filme, formas estáticas, linhas simples, um fundo puramente bidimensional, apontando para estruturas do mundo externo e literalmente "traçando" relações lineares entre ambiente, personagens e estados de consciência. A obra tende, assim, à abstração gráfica, em nome de uma representatividade mais ampla da condição humana e social, na qual as referências visuais não são, como, por exemplo, em $O$ Gabinete do Dr. Caligari, cenários arquitetônicos inspirados em pinturas expressionistas, mas se aproximam mais das gravuras em preto e branco de artistas como Emil Nolde, Erich Heckel e Karl Schmidt-Rottluff. 


\section{Da aurora à meia noite: a versão textual}

Um dos temas do expressionismo era o conflito da nova geração, sobretudo o dos filhos com os pais. O mesmo inseriu-se num âmbito maior, o conflito entre o artista e o burguês, bem como sua revolta contra a sociedade como um todo. Desse confronto, resultou uma esperança messiânica de um novo estado paradisíaco, um "novo homem", enquanto a experiência de sofrimento com o velho sistema levou o poeta expressionista a se estilizar frequentemente como mártir. Personagens que sacrificam sua vida por uma nova sociedade e pelo nascimento do novo homem são encontradas, sobretudo, em dramas expressionistas. A ideia de que algo velho deve morrer para que algo novo possa surgir, passando por desastres individuais ou coletivos, já se revela nos títulos de muitos livros e coletâneas expressionistas. Tod und Auferstehung (Morte e ressurreição) é o nome de um volume de poesias de Walter Hasenclever. A série mais famosa de livros expressionistas chamava-se Der jüngste Tag (O juízo final) e a antologia poética mais destacada intitulava-se Menschheitsdämmerung (Crepúsculo da humanidade). A ruptura com as convenções sociais, suposições falsas ou cegas, ocorre na literatura expressionista não sob a forma de um desenvolvimento contínuo, mas como rupturas, atos repentinos de arrebatamento e libertação, saltos irracionais, nem sempre motivados psicologicamente, da existência não autêntica para uma existência "verdadeira". Abstrai-se da realidade e das leis da causalidade, a fim de buscar a essência atrás das aparências. Essa atitude, frequentemente impregnada de traços fortes do pensamento cristão religioso, é visível no tom de sermão, no pathos messiânico com o qual o indivíduo é chamado a repensar a sua vida e seus valores, bem como na imagem do sacrifício humano ou na crucificação do homem moderno, um Imitatio Christi atualizado, na busca dessa renovação.

No que tange ao drama expressionista, o chamado Stationendrama ou "drama de estações" ganhou um lugar de destaque no que se refere a tais tendências, um gênero do qual também Da aurora à meia-noite faz parte. Desenvolvido a partir de formas mais antigas da tradição teatral e renovado por August Strindberg, esse gênero ofereceu, com sua estrutura sequencial de cenas mais soltas, a forma ideal de se distanciar da tradicional unidade mimética, fechada, densificada e psicologicamente consistente; em 
Korfmann, M. - Da aurora à meia-noite

vez disso, o Stationendrama configura-se como teatro de revista com suas cenas cortadas da realidade. Tais flashes estilizados do real são remontados e interligados, sobretudo através de um protagonista central que passa por experiências diversas, fornecidas pelos diferentes âmbitos sociais, sem que esses estejam integrados em um mundo heterogêneo. Nesse processo, o drama objetiva (cf. Kurt HiLler 1913), “extravasar concentradamente a essência” (ANZ/STARK 1982: 37) das coisas, através da desindividualização, a tipificação das personagens e a abstração, bem como da deformação do real em formas linguísticas de redução e extrapolação, que ultrapassam o mimético em direção a uma visão que poderia revelar os traços verdadeiros da existência, já que, conforme Kasimir EDSCHMID, em 1917,

[...] o verdadeiro não possa ser aquilo que parece realidade exterior. A realidade precisa ser criada por nós. O sentido do objeto ou do assunto deve ser esgaravatado. Não se deve estar satisfeito com o fato acreditado e anotado, deve-se refletir a imagem do mundo de modo puro e não adulterado. Mas isso é possível apenas em nós mesmos. Assim, todo espaço do artista expressionista torna-se visão. Ele não vê, ele olha. Ele não descreve, ele experimenta. Ele não reproduz, ele realiza. Ele não pega, ele procura. Agora, não há mais a cadeia dos fatos: fábricas, casas, doenças, prostitutas, gritos e fome. Agora, há a visão destes. Os fatos têm significado somente na medida em que a mão do artista ultrapassa estes para alcançar aquilo que está por trás (apud ANZ/ STARK 1982: 46).

É no contexto de tais reflexões e programáticas poéticas que surge a peça de Georg Kaiser. Não há indicadores conclusivos sobre o ano em que foi escrita. Muitos, como KASTEN (1990: 106) ou WALK (2007: 177), apontam o ano 1912 ou 1913, outros, como SCHÜRER (1975: 47), levantam a possibilidade de o próprio Kaiser ter pré-datado seu texto para, assim, fazer parte das primeiras obras teatrais expressionistas, junto com Reinhard Sorge, Der Bettler (O pedinte), de 1912, ou Der Sohn (O filho) de Walter HASENCLEVER, de 1914. Fato é que Da aurora à meia-noite foi impresso em 1916 e estreou no teatro nos Kammerspiele München em 28 de abril de 1917 sob a direção de Otto Falckenberg, com a presença do próprio Kaiser. A peça narra, em sete estações, divididas em duas partes (a primeira termina com a terceira estação), o calvário de um caixa de banco numa cidade pequena. Atraído por uma dama, o protagonista foge do banco e de sua vida medíocre e sem esperança com dinheiro roubado, mas fracassa em diversas situações da vida moderna da época e culmina com seu suicídio, estilizado 
Korfmann, M. - Da aurora à meia-noite

como crucificação no final da peça. Já o título generalizador (Von morgens bis mitternachts - Das manhãs às meias-noites) aponta para o fato de que não se trata de um caso isolado ou individual; tal percepção é reforçada ainda pela apresentação das figuras por funções como caixa, diretor, filha ou dama, sem nomes próprios. As diversas figuras funcionam como tipos e representantes, abstraídos de uma psicologização específica. Kaiser aponta para um episódio biográfico como ponto de partida para escrever a peça. "Queria viajar para Itália e fui a um banco para pedir a emissão de uma carta de crédito. Havia um caixa velho, aparentemente pobre, que executou a tarefa. Enquanto eu estava sentado e esperando, pensei que ele era uma pessoa bastante estulta. Por que ele mesmo não pega a carta de crédito e viaja para o Sul? Tinha eu um direito maior do que ele de desfrutar a vida? Mal cheguei em Roma, comecei a escrever uma peça sobre o assunto" (KAISER 1927). Numa conversa com Karl Heinz Martin em 1921, Kaiser traça sua intenção da seguinte maneira:

Não acredito que o homem-caixa precisa ser, de manhã à meia-noite, robô, escravo, criado, animal e supor uma ordem mais elevada acima de si, enquanto ele morre na sarjeta. [...] Não me recuso a limpar as escadas durante oito dias quando sei que os próximos oito dias pertencerão a mim, à minha disposição, meu desejo de vida, às tarefas que me ocupam por dentro! As pessoas não sabem destas possibilidades. Por isso, o poeta lhes mostra. (KAISER 1971: 565).

E proclama ainda: "A peça mostra a partida do indivíduo para a humanidade - o erro do ser humano como indivíduo - um "não" - a curva da estrada que leva a um muro de concreto: isso é que é Da aurora à meia-noite.” (KAISER 1971: 563).

A estrada do caixa que o leva ao muro, ou seja, ao seu fracasso no final, é dividida em sete episódios. O Stationendrama, peça estruturada em sete "estações" ou cenas, encontra sua raiz já na Idade Média como é o caso do Teatro dos Mistérios. No que se refere ao expressionismo, a importância dessa forma se deve, em grande parte, às peças de August STRINDBERg como O Caminho de Damasco (Till Damaskus - três partes, 1898-1904) e O Sonho (Ett drömspel 1902). Nesses textos as cenas são sequenciadas de forma solta e com diversas características estéticas, mas interligadas, sobretudo, através da presença do protagonista em ambientes diversos. $\mathrm{O}$ aspecto formal da divisão em episódios é, contudo, renovado e radicalizado no expressionismo através de uma independência maior entre as diversas situações em termos de uma lógica 
Korfmann, M. - Da aurora à meia-noite

interna coerente; também é enriquecido por meio de alterações inesperadas de níveis linguísticos e discursivos. Em Da aurora à meia-noite, o espectro linguístico vai de um naturalismo pleno até o mais radical expressionismo de diálogos em staccato, incluindo um extenso monólogo lírico, sem que a peça apresente um centro aparente; os episódios são interligados apenas pela figura do caixa em suas passagens por diversos níveis experimentais.

Se formos procurar uma cena mais "significativa", talvez se possa apontar para o encontro do caixa com a morte, no final da primeira parte, um longo monólogo, muito apreciado pelo poeta Rainer Maria Rilke (cf. SCHÜRER 1975: 85) e possivelmente inspirado pelo desenho "A morte na árvore" de Angelo JANK, publicado na revista Jugend, em 1897, uma ilustração para um poema de Paul Heyse (Id.: 17-20). Mas de maneira geral, a busca fracassada pelo "novo homem", pela renovação, o pulo frenético fora da existência rotineira e opressiva para a essência da vida, não é apresentada de forma evolutiva, mas sequencial. As estações nessa corrida sem fôlego atrás da experiência, do acontecimento, da vida pulsante, propiciam encontros desapontadores em diversos âmbitos sociais: nem a beleza, a arte, a família, o espetáculo de massa, o erotismo ou o exército da salvação oferecem uma perspectiva promissora. Todas as áreas são corrompidas pelo dinheiro e apenas atuam na base da exploração. A viagem de um dia do caixa pelas ofertas do real não se revela como o caminho da cruz seguido pela ressurreição, mas como um círculo de solidão sem saída. O protagonista se torna um cristo fracassado na época do capitalismo e encontra seu fim simbólico na cena final com alusões à crucificação: o caixa "está afundado de braços abertos na cruz costurada da cortina. Seus gemidos soam como um 'Ecce' - seu suspiro como um 'Homo"' (KAISER 2010: 74).

Se a temática não apresenta maiores inovações ao relatar a história de um homem resignado de meia-idade que, impulsionado por um encontro casual com a mulher atraente, rompe com sua existência e se joga de modo desesperado nos turbilhões de experiências, terminando em um previsível fracasso, outros recursos chamam a atenção do público e da crítica da época: o dinamismo cênico, as alterações de estilos discursivos e, consequentemente, certa fragmentação narrativa, oscilando entre a linguagem coloquial, o pathos, a ironia e o lírico. Podemos, nesse caso, constatar 
Korfmann, M. - Da aurora à meia-noite

dois polos interpretativos: um que avalia tais procedimentos dentro da tradição teatral e outro que os vê em analogia com a linguagem fílmica. Em trabalhos mais recentes sobre Da aurora à meia-noite, como o artigo da já citada Cynthia WALK, menciona-se, frequentemente, apenas aquelas críticas que explicam a estrutura sequencial da peça como empréstimo da linguagem cinematográfica, a fim de comprovar o impacto no novo medium filme sobre um medium tradicional, neste caso, o drama. Assim, ganham lugar privilegiado na argumentação resenhas como as do renomado crítico Alfred Kerr, que escreve à época que "tudo isso evoca em mim a ideia de truques, que soam como algo profundo sem ser profundo" (KERR 1965: 256), ou o comentário de Bertold Brecht, ao aludir à montagem fílmica da cena na última estação da peça: "Kaiser está encenando uma tomada fílmica" (BRECHT 1967: 58). Cynthia Walk ainda vai além das insinuações bastante gerais de Kerr ou Brecht. Na busca por um modelo fílmico semelhante às alterações estilísticas e às diversas dinâmicas das cenas teatrais da peça de Kaiser, a autora tenta explicar o formato de Da aurora à meia-noite a partir de uma suposta influência da programação cinematográfica da época com seu mix de cenas curtas e variadas.

\begin{abstract}
An examination of cross-media relations in Weimar culture begins with the changed circumstances of literary production that place German drama in the orbit of cinema well before the 1920s. It shows that the impact on Kaiser's play of 1912 is more pervasive than the general allusion to montage suggests. The filmic connection is specific and historical, referencing the milieu, the formal conventions and the exhibition practice of early German cinema as well as the persona of its first international star. Like its characteristic program of short films, Von morgens bis mitternachts entertains with variety, offering the spectator a sequence of cinematic genres in a display of diverse actualities and story scenarios (WALK 2007: 178).
\end{abstract}

Assim, o chamado Nummernprogramm, que consiste tradicionalmente na apresentação de oito a dez filmes curtos, misturando cenas documentais com encenações ficcionais e de apelo heterogêneo, serve, para Walk, como referência para justificar o argumento que se trata de uma peça com claros empréstimos estruturais dessa fase cinematográfica. O que diferencia o drama de Kaiser de outros experimentos formais da época é, conforme a autora, 
Korfmann, M. - Da aurora à meia-noite

[...] a structure that replicates the standard exhibition practice of early cinema, called the numbers program. The typical format of that program in 1910 consisted of ten short films of documentary and fiction genres with heterogeneous appeal. The sequence was not random but strategically designed to entertain the audience through diversity and contrast. Organized overall in two parts with an intermission, the program culminated in a spectacular finale featuring a star personality. Von morgens bis mitternachts employs a similar structure. Its scenario is fragmented into discrete episodes without spatial continuity. Each episode places the protagonist in a new setting with a different group of secondary characters. Sudden shifts in style, from naturalism to visionary expressionism, introduce further discontinuities in the text which cannot be reconciled by a title that gestures toward containment through a temporal reference more metaphorical than literal. With its many different settings, its constantly changing ensemble and contrasting styles, Kaiser's play not only functions like the numbers program of early cinema, its individual scenes also correlate with the film genres represented in that program. (WALK 2007: 180).

Como gêneros fílmicos, Walk, então, vê paralelos entre a primeira parte do drama e os episódios fílmicos do Nummernprogramm que apresentam crimes, comédias de identidades trocadas, paisagens cênicas e ilusões visuais criados por efeitos especiais, enquanto a segunda parte do drama se ocuparia com cenas da vida contemporânea, dança e um grand final surpreendente.

No nosso entender, tais tentativas de explicar, sob a perspectiva de uma intermedialidade destacada da época, a relativa heterogeneidade da peça a partir das apresentações de curtos filmes aleatórios da fase inicial do cinema, carecem de duas condições básicas. Primeiro, as críticas da época nem de longe destacam de maneira uniforme tal caráter fílmico da peça, como as citações de Kerr ou Brecht podem sugerir. O citado crítico Alfred Kerr, por exemplo, era inimigo declarado do seu colega Herbert Jhering, um defensor do teatro de Kaiser. Consequentemente, Kerr desqualifica sua peça como "obra sem pensamento ou sangue", uma obra de pura "técnica" onde se vê, "em vez do poeta, sempre um construtor de andaimes" (KERR 1964: 256-57) e destaca, no contexto de uma suposta "industrialização das artes" por Kaiser e sua carência de qualidade poética, o filme como novo fenômeno cultural resultante do progresso técnico. Na leitura de dezenas de outras críticas da época, nota-se, de fato, que o caráter episódico do drama ocupa um dos lugares centrais nas discussões, sem que se deduza uma influência intermedial do cinema sobre a peça de Kaiser. Richard ELCHINGER, por exemplo, fala, referente à encenação em Munique de 1917, de uma "sequência 
Korfmann, M. - Da aurora à meia-noite

diversificada de episódios", de "sete imagens", influenciadas por autores como Christian Dietrich Grabbe, Frank Wedekind ou Carl Sternheim, mas lamenta que Kaiser não consiga alcançar uma nova "unidade estilística" e, assim, sua habilidade técnica (discursiva) se sobrepõe à "força poética" (apud RÜHLE 1967: 58-59). O mesmo desconforto com a falta de homogeneidade transparece nos comentários de Richard BRAUNGART, quando este avalia que Kaiser ainda "luta com os elementos constitutivos da modernidade literária", mas que oferece pelo menos a perspectiva de encontrar uma “síntese de novos valores que apontam para o futuro" (apud RÜHLE 1967: 60-61). Parecida com essa avaliação é a resenha da Frankfurter Zeitung, de 20 de maio de 1917. Ela julga que a nova exigência formulada nessa peça no que se refere à "velocidade, coloração e intensidade acima de tudo", ainda tem caráter apenas programático. Argumenta que o "dilaceramento mental do caixa" espelha-se na dissonância do drama, sem que o autor consiga gerar disso uma forma orgânica, o que resulta, segundo a resenha, numa "cacofonia insatisfatória" (apud RÜHLE 1967: 62). A crítica referente à segunda encenação, em dezembro do mesmo ano em Viena, chega a conclusões semelhantes. Richard SPECHT destaca a dificuldade do público de acompanhar as permanentes alterações estilísticas, de "sempre diferenciar entre o distorcido e profundo" e de precisar permanentemente "completar o sentido desta densificação linguística" que "explode, sem consideração", em cada momento de maneira inesperada, "às vezes de forma repugnante; em outros momentos, de forma fascinante ou chocante" (apud RÜHLE 1967: 62). Em janeiro de 1919, a peça de Kaiser finalmente estreia em Berlim. No Berliner Tageblatt de $1^{\circ}$ de fevereiro de 1919, o crítico Fritz ENGEL considera Kaiser "o virtuoso mais impressionante do drama europeu", enfatizando, sobretudo, a velocidade frenética com que a peça se desenvolve. Esta faz com que o espectador vivencie, sem fôlego, o dia do caixa. Kaiser, desenhando "a cena da Corrida dos Seis Dias com frases violentas e ofegantes, numa imagem infernal", possui, ele mesmo, "a velocidade de um arranque final". Sua peça “[...] traça figuras, as faz desparecerem, outras vêm, ele nos joga um mundo inteiro de pessoas na cara. [...] Todos os meios do teatro ele forma conforme sua vontade, tanto os reais como os irreais. [...] Uma fantasia sem limites revolve em todos os êxtases. [...] A linguagem se afia para as mais densas fórmulas linguísticas. Esta peça não foi escrita, ela foi telegrafada." (Cf. ENGEL 1919). 
Como se vê nesses curtos resumos, não havia alusões ao novo medium fílmico na maioria absoluta das críticas e, consequentemente, os comentários de Brecht ou Kerr são, antes de tudo, exceções e não regra. Obviamente, pode-se, mesmo assim, comparar a estrutura de Da aurora à meia-noite à linguagem fílmica no que se refere a seu caráter sequencial. Ao se estudar os filmes narrativos da época, dificilmente se encontra um exemplo que apresente uma montagem tão dinâmica e variada como a que nos oferece a peça de Kaiser. Pelo contrário, nessa linha de pensamento seria até mais fácil argumentar que os princípios da montagem desenvolvidos posteriormente, nos anos 1920, podiam recorrer ao drama de Kaiser e outras obras literárias para se configurar. Menos plausível ainda, e este é nosso segundo ponto, seria uma associação próxima entre os Nummernprogramme do início do cinema, que não apresentam nexo algum entre seus curtos trechos fílmicos, e a peça de Kaiser que se baseia sobretudo no "caminho da cruz" do caixa, um protagonista presente em todas as cenas da peça e onde cada uma delas representa mais uma esperança frustrada e desapontada da figura central. Há, sim, alterações radicais em termos estilísticos, discursivos, dinâmicos ou poéticos, mas todas elas giram em torno do motivo central da peça, a questão do dinheiro. "Compra-se sempre menos do que se paga. E quanto mais se paga, menos vale o produto" (KAISER 2010: 72-73), essas frases do caixa são variadas, transformadas e revestidas de diferentes formas durante as sete cenas de Da aurora à meia-noite, formando, junto com a figura do próprio protagonista, uma linha narrativa clara e destacada.

É verdade que esta não se apresenta de maneira homogênea e nem numa continuidade discursiva, mas de maneira oscilante, fragmentada e cheia de rupturas e pulos inesperados. Não se trata, portanto, de números ou imagens aleatórias, e sim de variações a partir de um ponto referencial temático, ideológico e estruturador. É justamente esse conservadorismo relativo de Kaiser que o torna um autor clássico do expressionismo. Ele mantém, juntamente com todas suas inovações estéticas, uma constelação de figuras e diálogos ainda recapituláveis, sem dissolvê-las num constructo sintético de formas, cores, movimentos e sons, como pretendiam outros expressionistas como Wassily Kandinsky, Oskar Kokoschka ou August Stramm. Isso propiciou que ele fosse, de um lado, aclamado pelo público e por parte da crítica e, de outro, objeto de 
Korfmann, M. - Da aurora à meia-noite

reprovação pelos vanguardistas mais radicais, como os autores da revista Der Sturm que viam em Kaiser um "meio-expressionista” (apud SPRENGEL 1990: 697), um "explorador da conjuntura" (STURM-BÜHNE 1918: 4) ou julgavam que "esse Kaiser expressionista coroado pela imprensa é um zero completo" (WALDEN 1924: 66).

\section{Da aurora à meia noite: o aspecto visual}

Além dos pontos construtivos acima mencionados, há ainda a questão visual da encenação, que contribui claramente para a configuração de uma unidade que não apenas cria um ambiente atmosférico diferenciado, mas contribui para sublinhar e enfatizar a essência textual da peça. De maneira geral, o aspecto cênico é um dos pontos de destaque no teatro expressionista, inovando, talvez, o teatro de forma mais radical do que o próprio texto de partida. Por isso, consideramos oportuno apontar, a seguir, para esse elemento de forma mais generalizada para depois voltarmos à nossa peça central, Da aurora à meia-noite.

Devido às tensões políticas resultantes da guerra, os dramas expressionistas, muitos deles escritos entre 1910 e 1914 e impressos entre 1912 e 1916, ganharam encenações apenas a partir de 1916/1917. Pontos marcantes são a encenação, em Praga no ano de 1916, de Der Sohn (O filho), de Walter HASENCLEVER, escrito em 1913 e impresso em 1914; em 1917, estreia em Frankfurt Die Bürger Von Calais (Os cidadãos de Calais), de Wolfgang KAISER, e no mesmo ano, Da aurora à meia-noite, do mesmo autor, em Munique. Entretanto, é apenas com a conquista do centro da vida cultural, Berlim, que o drama expressionista ganha uma ressonância mais destacada. Como vimos, havia discussões polêmicas sobre a qualidade textual e a capacidade dramáticoestrutural do drama de Kaiser, críticas que se estenderam também para outras obras e autores. Mas os dramas expressionistas da época, com seus diversos formatos estilísticos e conceituais, ganharam mais uniformidade, um estilo reconhecido e, conforme DIEBOLD (1921), também mais força dramática, através da encenação nos palcos sob a influência visual da pintura e da obra gráfica expressionista. Já em 1916, 
Korfmann, M. - Da aurora à meia-noite

Walter HASENCLEVER formula, em seu manifesto Das Theater von morgen, dois aspectos centrais dessa nova concepção: o caráter antirrealista dos cenários, criando espaços "puros" frente ao ambiente externo e a iluminação elétrica como elemento formador do cenário: "Não coloquem mais árvores no palco: criem luz e sombra; não vistam mais fantasmas" (HASENCLEVER 1988: 268).

Um exemplo de tal realização encontra-se na encenação de 1917 da peça Der Bettler (O pedinte) de Reinhard Johannes SORge. O crítico Heinz Herald escreve: "Nada é bloqueado, nenhuma construção reduz e diminui o espaço. Do espaço grande, preto, que tem algo de intocado, ainda não preenchido, ilimitado, a luz retira um pedaço: aqui se passa a ação" (HERALD 1918: 30). Constam duas tendências básicas: a mencionada redução do palco para um espaço vazio, preto, com nenhuma ou pouca referência visual e dos efeitos de luz ou a insinuação de ambientes através de poucos traços pintados, estruturando "a encenação de forma rítmica e temporal" (ZIMMERMANN 1997: 60), bem como a tentativa de destacar a objetivada "essência" também através de um cenário de caráter arquitetônico, ganhando grande plasticidade com suas construções de níveis atravessados, tortos e inclinados. No que tange à questão da iluminação, a encenação de Der Sohn (O filho), de HASENCLEVER, em Mannheim no ano de 1918, apresentou o novo uso da luz de maneira marcante, retomando e intensificando tendências já visíveis um ano antes em Der Bettler (O pedinte), de Reinhard SORGE. Destaca-se o uso de um holofote móvel seguindo a personagem, um "dedo branco feito de um rio de luz" (DiEBOLD 1921: 242), marcando faces e locais ou impulsionando os protagonistas pela ação. É óbvio que o uso da eletricidade nos palcos dos anos 10 e 20 do século XX e, consequentemente, as novas possibilidades da iluminação elétrica não resultaram em uma única forma de trabalhar esse medium. Bertolt BRECHT, por exemplo, proclama, dentro de sua concepção de estranhamento, que a exibição aberta da iluminação - e não seu efeito ilusório - revela ao espectador o caráter artificial do teatro, destruindo, assim, algo de sua ilusão de assistir a uma ação momentânea, espontânea, não ensaiada e real. Diferente de BRECHT, o diretor Max REINHARDT usava a luz justamente para criar tais efeitos de ilusão, de espaços, de sombras e iluminações indiretas, bem como elemento para reforçar a coreografia de massas no palco. No teatro expressionista, a luz ganha uma força destacada no âmbito 
de seus espaços abstratos aparentemente infinitos. É sobretudo lá que a iluminação serve para dividir tais espaços e desenhar comentários cênicos. Com isso, a luz torna-se um meio central para a desmaterialização do palco, bem como medium de uma experiência sensorial e sensual visível.

É nesse contexto que se situa o trabalho do diretor Karl Heinz Martin. Já durante sua atuação como diretor do Thalia-Theater em Hamburgo, ele apresentou, em setembro de 1918, Da aurora à meia-noite. Roma Bahn, esposa de Martin, fazia o papel da moça do exército da salvação, um papel que ela também representou na versão fílmica, dois anos mais tarde. Os jornais de Hamburgo destacam que Martin encenou a peça como "experiência espiritual, completamente desligada da realidade" (HAMBURGER NACHRICHTEN, 30 de setembro de 1918). O clima irreal foi reforçado pela atuação dos atores, que agiam como "marionetes ou bonecos movimentados por fios" (HAmburger Echo, $1^{\circ}$ de outubro de 1918). O cenário, “com seus detalhes em cinza, postos em frente a um fundo preto", foi considerado uma "reminiscência dos gráficos terrivelmente distorcidos em preto e branco" (HAMBURGER NACHRICHTEN, 30 de setembro de 1918). As razões teóricas de tais procedimentos, as reflexões básicas de MARTIN à época sobre o teatro e o expressionismo, são formuladas no mesmo ano em um dos poucos textos teóricos escritos por ele que se chama Die Bühne und der Expressionismus (O palco e o expressionismo) do ano de 1918. Nele, Martin concebe o expressionismo como contraposição ao impressionismo e o caracteriza pela "apropriação emocional da essência interior, da alma da natureza, da alma do mundo, sem levar em conta a imagem natural do mundo", uma Gênesis do mundo, a partir da própria experiência gerada no sentimento subjetivo. Cada sujeito sente em si "o centro cósmico do mundo", materializado na obra e sua encenação; a encenção deve apresentar essa sensação e experiência em uma forma de maior redução e simplificação. Em vez do olhar reprodutivo e ilusionista em forma de prisma, característico do impressionismo, Martin reivindica para a obra expressionista e, por consequência, para a sua encenação no palco, sua libertação de formas naturais e a situa num espaço de experiência mental, interior e emocional, marcado visualmente pela redução e simplificação do palco ao essencial. Com isso, defende uma concepção oposta ao teatro tradicional com seus "brinquedos de luxo" e sua ênfase em "ostentação, refinamento e sua fixação em 
Korfmann, M. - Da aurora à meia-noite

espetáculos de magias de efeito na base da maquinização", que degrada o texto literário apenas em um pretexto secundário e torna o palco um mero lugar para "atrações técnicas". Consequentemente, objetiva um teatro desnudado de toda aparelhagem técnica. O palco, a cena e os gestos devem emergir da palavra e da sua força sonora, formando um espaço teatral onde "uma delicada insinuação, um arabesco do lugar" e um "ornamento das coisas" configuram o elemento cênico. Seu objetivo não é mais a representação de "atmosferas impressionistas" ou de um "pedaço de vida" no sentido naturalista, mas a "elevação da realidade", a encenação da expressão potencializada da experiência íntima subjetiva, sem que o sujeito se torne objeto de interpretações psicológicas; em vez disso, é portador de uma ideia ativa, nele acontece o "drama do mundo" que nele se torna visível.

Martin, juntamente com seu cenarista Robert Neppach, tenta transformar tais reflexões teóricas em práxis em seu teatro Die Tribüne, fundado em 1919: um lugar relativamente pequeno para 296 espectadores em Berlim Charlottenburg, longe dos bairros tradicionais dos varietées e teatros da cena berlinense. Ele manda instalar um palco reduzido e achatado, um pódio, com iluminação simples acima da primeira fileira. Não havia separação entre palco e espaço dos espectadores. Em busca da essência pura, estreia a peça Der Retter (O salvador), de Walter HASENCLEVER, sem qualquer cenário e Die Entscheidung (A decisão), do mesmo autor, apenas com alguns móveis e um arco pintado como fundo. Conforme relatos da época, o público ficou sobrecarregado ao enfrentar um palco quase vazio. "Nunca uma floresta de conto de fada de Max Reinhardt ou um castelo de ópera tinha desviado tanto a atenção do público como essa parede vazia e desafiadora" (JACOBS 1920/1921: 302). Já a próxima encenação no mesmo ano, a peça Die Wandlung (A transformação), de Ernst TOLLER, catapulta Martin e seu teatro para o centro das atenções e foi de grande influência sobre a cena expressionista. Martin modifica o texto de Toller, na época preso por sua participação na revolta pós-guerra e no governo comunista em Munique: em vez de terminar a história com o apelo político para a revolução, como era na versão original, Martin o substitui por um apelo à humanidade: "Marchem, mas não derramem sangue, descubram em primeiro lugar o homem dentro de vocês mesmos" (cf. SCHORLIES 1971: 85). Ele também modifica as indicações contidas na texto de Toller em relação a um 
cenário de dois espaços, um para as cenas realistas e outro para as de sonhos. Assim, instala no fundo uma cortina preta e coloca, para as respectivas cenas, uma parede com desenhos simples, distorcidos, que apenas traçam e apontam para os locais da ação, além de usar alguns poucos objetos como arame e camas. Com isso, evoca a sensação de fragmentos e deformação, espelhando, assim, o estado mental do protagonista com o ambiente reduzido ao elementar e apenas representado de maneira alusiva. Os motivos centrais dos diversos ambientes foram "transformados, comprimidos em reduzidas imagens dramáticas e caricaturados de forma derrisória em reduções bizarras" (Bz AM MitTAG 1919).

Martin estende esta característica visual para parte dos atores: Os mortos são vestidos de roupa preta, na qual é pintado, em branco, o esqueleto, e as faces são maquiadas como caveiras. Também a iluminação é usada nesse sentido. Às vezes um cone de luz destaca apenas um pequeno círculo do pódio. As cenas realistas são iluminadas de maneira forte, enquanto as de sonho apenas através de feixes de luz. Assim, as roupas pretas tornam-se invisíveis de maneira que apenas os ossos pintados brilhem no escuro. A crítica elogia a encenação como um acontecimento histórico, que não só supera todas as tentativas anteriores de Martin, mas também seria a solução única para o texto, tornando, através de seus cenários indicativos e alusivos, as estruturas narrativas e mentais bem mais visíveis do que em uma encenação de caráter realista (cf. SCHORLIES 1971: 88). Mas Martin não era o único diretor a inovar assim o cenário em direção ao abstrato e à inclusão dos corpos dos atores no visual cênico. Encontram-se exemplos de tal tendência já antes da Primeira Guerra Mundial. Em 1909, o drama Mörder, Hoffnung der Frauen (Assassinos, esperança das mulheres), escrito em 1907 pelo pintor e autor Oskar KoKOSCHKA, foi encenado no Teatro do Jardim por estudantes da Escola Artesanal de Viena, em Praga, no âmbito de uma Mostra de Arte. Dentro da programática expressionista, que tinha a intenção de, através de linhas e traços "primitivos", revelar a agressividade das relações sociais escondidas embaixo do véu civilizatório, Kokoschka queria tornar visíveis as pulsões sexuais atrás das fachadas do sentimento burguês. A peça foi publicada na revista Der Sturm, junto com quatro ilustrações, mostrando um casal em luta, vestido com poucas roupas. Nelas, estão pintadas veias, e as cabeças são permeadas por feixes de nervos, tornando o interior das 
Korfmann, M. - Da aurora à meia-noite

figuras perceptível na superfície. E, com o mesmo visual, a peça foi encenada em 1909, enfatizando, assim, o caráter tipográfico, livre de dimensões psicológico-individuais (cf. KoKOschKa 1956: 455). Em 1917, Richard WEICHERT encena em Mannheim Der Sohn (O filho), de Walter HASENCLEVER, na mesma linha reducionista. "Deduziu-se, a partir das emoções da tensão interior, o espacial, criando assim uma decoração reduzida, cujas raízes vinham da linguagem poética, da abreviação da palavra que é a expressão mais concisa" (WAGNER 1926: 125). O palco consistiu de um espaço preto onde se destacavam contornos de janelas e portas pintadas com tinta branca gritante. A iluminação destacava, através de um cone de luz, o protagonista, criando, assim, um espaço fantasioso estilizado, totalmente antirrealista e rejeitando por completo qualquer representação naturalista ou ilusionista no sentido mimético. Em vez disso, nota-se uma tendência à abstração em que, a partir de linhas tortas e deformadas, emergem traços de objetos e indicações referentes ao ambiente. A simplificação cênica certamente era também resultado da escassez de matérias durante e logo depois da Primeira Guerra Mundial, como alegou Lotte EISNER (1958), mas essa falta veio ao encontro das tendências estéticas da própria concepção expressionista, seu objetivo de "densificar o sentimento, destacar o essencial e impulsionar o desejo humano intensivo" (JACOBS 1920/1921: 301).

A configuração gráfica explicitamente rudimentar dos diversos elementos, interligados organicamente com as cortinas espaciais do fundo, alcançou uma ressonância tão forte como outra tendência paralela do teatro expressionista: a tendência para uma "arquitetonização" da cena, objetivando uma plasticidade maior através da divisão do espaço teatral, sobretudo através da escada como elemento para criar espaços tridimensionais e marcar pontualmente áreas de maior ou menor atenção e significado, visualizar contextos de forma simbólica e dinamizar o espaço pela plasticidade móvel do ator. É desse contexto que surge o filme O Gabinete do Dr. Caligari. Ambos, tanto o filme de Robert Wiene como o teatro expressionista arquitetônico, também se distinguem das encenações de Kaiser no Tribüne, bem como sua versão fílmica de $D a$ aurora à meia-noite pelo uso de cores. Enquanto Martin se restringe no sentido da objetivada redução e simplificação, ao contraste preto e branco, apontando, assim, para estruturas básicas e traços elementares de ambientes e processos mentais e 
aproximando-se das gravuras, havia, no lado oposto, encenações baseadas na força das conhecidas cores gritantes das pinturas expressionistas. O uso excessivo da cor no cenário pode ser compreendido como potencialização do real e enriquecimento simbólico. "Ela ganha significado próprio como parte do Gesamtkunstwerk", torna-se “efeito dramático e ganha valor como meio expressivo simbólico" (RUNGE 1962: 144). Assim, as cores não são usadas em relação ao respectivo objeto, mas frequentemente marcam, de maneira gritante, um aspecto interpretativo abstraído. A coloração intensiva e gradual funciona, assim, como meio central de estruturação da cena e da encenação. Quanto à encenação da peça Hölle Weg Erde (Inferno Caminho Terra) de Georg KAISER, no teatro Lessing em Berlim, Herbert JHERING escreve sobre a cor: "Sua composição era uma chamada sonora, um grito audível". Ouvia-se "o drama de maneira colorida. As nuances das cores são as nuances da energia. E as cores continuam a arder nos atores." (JHERING 1974: 128-129). E o próprio Martin aplicaria mais tarde, na sua encenação de Brända tomten de STRINDBERG em Berlim, em 1920, tais efeitos. Em frente a um fundo violeta, os habitantes usam roupas vermelhas, amarelas, verdes ou azuis, enquanto que apenas o "estranho", retornando à sua cidade, passa pelas superficiais manchas coloridas burguesas vestido em preto e branco, marcando, nessa dissonância, as diferentes concepções de vida.

Resumindo: havia duas tendências para alcançar o objetivo básico do teatro expressionista, que explicamos através de propostas como a densificação, a revelação das estruturas básicas escondidas atrás da superfície, que levam ao destaque do essencial e, consequentemente, abstraem a reprodução mimética do real. A busca pela essência atrás das aparências resulta no abandono do pensamento e da narrativa baseados na causalidade em favor de formas resultantes da visão interior. A primeira tendência consiste na "arquitetonização" da cena, na divisão espacial horizontal e vertical, sobretudo através de escadas e rampas ou construções tortas, de esguelha, bem como cores gritantes para indicar tendências essenciais numa dramaturgia de cores e elementos arquitetônicos de valor simbólico; a segunda afigura-se como um asceticismo visual, limitando o palco a um espaço parco, uma área preta com poucas linhas insinuativas, traçando em pinceladas brancas as respectivas essências de maneira 
rudimentar. Para encenar Da aurora à meia-noite, Martin optou, evidentemente, pela última opção. E a manteve como ponto de partida para sua versão fílmica.

\section{Da aurora à meia-noite: o filme}

Pode-se apenas especular sobre os motivos que levaram a uma transposição fílmica da Da aurora à meia-noite. Gerald KöHLER, por exemplo, comenta que "as sequências das imagens e os lugares urbanos bem conhecidos, como O Palácio de Esporte de Berlim, os cabarés ou o banco vieram ao encontro de uma adaptação fílmica.” (2010: 174). Contudo, esse comentário também valeria para muitas outras peças na tradição do Stationendrama. Também é possível que Robert Neppach, cenarista de Martin, tivesse feito os contatos necessários no âmbito cinematográfico, já que ele trabalhava desde outubro de 1919 para uma empresa chamada Centaur-Filme, onde também atuava Hans Janowitz, um dos autores do script de $O$ Gabinete do Dr. Caligari, além de diversos atores e atrizes dos teatros de Max Reinhardt (cf. DillmanN 2010: 278). Outro fator a ser levado em conta é que o expressionismo tinha conquistado status de moda em 1920 e penetrado em boa parte da vida cultural. A peça de Kaiser tinha virado um sucesso e Martin era um dos diretores destacados na cena teatral, sobretudo relacionado às encenações expressionistas. Assim, uma transposição fílmica também poderia representar uma possibilidade de obter reconhecimento e lucro no medium fílmico. $\mathrm{O}$ fato é que Da aurora à meia-noite foi filmado entre maio e julho de 1920, ou seja, iniciaram-se os trabalhos dez semanas após a estreia de O Gabinete do Dr. Caligari, como relata a revista Lichtbild-Bühne (20/1920: 29 e 29/1920: 35). A filmagem foi produzida pela modesta empresa Ilag-Film dos cenaristas Herbert Juttke e Georg Isenthal. Juttke também escreveu, juntamente com Martin, o script do filme.

O autor Georg Kaiser não parecia estar muito interessado na filmagem da sua obra. Jürgen KASTEN (2003: 160) supõe motivos financeiros para que ele finalmente concordasse com a mesma, sob a condição de que o famoso Karl Heinz Martin fosse o diretor. O contrato entre Kiepenheuer, a editora de Kaiser e o Ilag-Film foi finalmente 
Korfmann, M. - Da aurora à meia-noite

assinado em maio de 1920 e as filmagens iniciaram-se imediatamente. Martin colaborou para seu filme com representantes de duas media: do lado teatral, destaca-se a colaboração de Robert Neppach, o cenarista responsável por sua famosa encenação de Die Wandlung (A Transformação), de Ernst TOLLER, no teatro Tribüne em Berlim. Entre os atores, havia Ernst Deutsch como representante destacado de atuação expressionista no teatro, mas também ator em diversos filmes desde 1916 e Erna Morena, atriz com longa carreira cinematográfica. A gravação e o lado fílmico-técnico ficaram sob a responsabilidade de Carl Hoffmann, um diretor de fotografia com grande experiência no cinema. E Martin ainda convidou amigos como o escritor Max Herrmann e sua esposa Leni para atuar em papeis menores.

Apesar de fazer parte da lista da distribuidora Henry-Müller-Monopolfilms e passar pela censura, como todos os filmes da época, o filme nunca foi exibido comercialmente. Rudolf KURTZ mencionou, em uma frase no final de sua crítica acerca do filme de 1926 (2007: 70), que este supostamente fez algum sucesso no Japão. Provavelmente referia-se a um artigo de 1923 do então presidente da sociedade artística teuto-nipônica de cinema, em que o mesmo relata que "o 'Dr. Caligari' granjeou boa ressonância [no Japão] e encontrou uma compreensão do nosso público comparável a recepção dos filmes 'Genuine' e 'Da aurora à meia-noite', realizados de maneira parecida, que alcançaram um grande sucesso. Sem dúvida, são justamente tais filmes, com certo caráter artístico, que conquistaram muitos amigos aqui" (KRICHI OKAJIMA 1923: 18). E um crítico japonês que viu o filme em 1922 no cinema Hongo-za comenta: "Este filme parece ser um dos melhores entre as películas expressionistas mostradas até agora no Japão. Em Caligari ou em Genuine achei a narrativa bastante tediosa, o que não é o caso desse filme. O momento estático e cinético forma sempre um belo contraste e as diversas cenas seguem numa sequência fluida, criando um processo que torna o filme bastante impressionante" (apud DEGENHARDT 2010). KASTEN informa que Lotte Eisner, na época Conservatrice da Cinemateca Francesa, entrou em contato com o Instituto Japonês do Filme para confirmar tal informação. Verificou-se que a cópia japonesa não tinha letreiros. Mas em 1987 encontrou-se ainda na Alemanha, de forma surpreendente, o registro da censura de 1921 que, como praxe, listava os letreiros da versão original, nesse caso em torno de cem. Da aurora à meia-noite voltou a ser 
Korfmann, M. - Da aurora à meia-noite

exibido apenas em 1968, numa mostra interna para estudantes da Universidade de Frankfurt e depois, em 1978 e 1984, apresentado na programação da televisão da Alemanha Oriental. O filme foi restaurado em 2009, com os letreiros e se tornou, desde maio de 2010, disponível em DVD, editado pelo Deutsche Filmmuseum München.

Diferente de $O$ Gabinete do Dr. Caligari, escrito especificamente para o cinema, Da aurora à meia-noite carrega, evidentemente, o peso da transposição de uma peça de grande sucesso e de destacados experimentos e inovações estilistas para o medium cinematográfico mudo, precisando compensar a qualidade textual por meios fílmicos e visuais, seja em relação aos cenários, seja por causa da atuação dos atores. É consequente que tanto a própria produção, bem como as críticas da época, nas raras ocasiões em que o filme foi apresentado, reforcem tais aspectos. Na sua estreia para um público seleto, o crítico Josef AUBINGER constatou: “A força do filme origina-se menos de sua ação do que de sua qualidade explicitamente visual. Criaram-se imagens que expulsam quase que por completo a palavra, e mesmo onde há letreiros, eles registramse no cérebro através de sua forma tópica e não perturbam o fluxo visual" (apud DEGENHARDT 2010). O filme foi anunciado como o primeiro que se apresenta nas cores fundamentais de preto e branco, não tentando esconder sua configuração visual essencial através, por exemplo, de películas pancromáticas, uma coloração artificial posterior ou a pintura de cenários em certas cores para obter efeitos de cinzas na película. Willy HAAS comenta em 1922: “Tentou-se forçar as imagens em movimento numa antítese em preto e branco, provavelmente levando em consideração o caráter incolor do cinema e levando isso às últimas consequências: em termos de teoria artística e literária totalmente consequente" (apud DEGENHARDT 2010). O Film-Kurier de 1922 avalia que, com Da aurora à meia-noite, "o expressionismo se aproxima bem mais das possibilidades fílmicas do que Caligari. A representação dos objetos e a atuação formam uma unidade, apoiada ainda através das pinturas em branco [sobre os corpos]" (FILMKURIER 1922). E Rudolf KURTZ destaca que "Martin condensou bem a intensidade do processo", transportou o ritmo da existência das figuras "para os gestos” (2007: 69), construindo "a representação a partir da dinâmica da ação". KURTZ ainda enfatiza o papel central dos cenários construídos por Neppach: “Objetos, paisagem, decoração e mobília - tudo objetiva um efeito gráfico linear, um efeito de movimento de áreas, 
Korfmann, M. - Da aurora à meia-noite

espaços e linhas em claro e escuro" (2007: 69). Não é difícil interligar aqui a práxis teatral de Martin em sua Tribüne, a exemplo de sua encenação em Die Wandlung (A transformação), de 1919, com seu trabalho fílmico. Em ambos havia um fundo preto com desenhos simples, distorcidos que apenas traçam e apontam para as respectivas localizações. A visualidade fragmentada, deformada e distorcida reduz ao elementar o ambiente perspectivado pela visão do protagonista e apenas representado de maneira insinuada. Os próprios atores também se integram em ambos, filme e práxis teatral, nesse cenário, ao se estenderem as linhas gráficas e bizarras sobre suas faces e corpos. Todavia, mesmo com todos esses pontos de convergência entre palco e cinema, Martin vai além de uma mera filmagem de uma encenação teatral, inserindo uma cena nova do submundo do crime e experimentando explicitamente com meios fílmicos. Junto com o operador de câmara, Carl Hoffmann, Martin estrutura o texto através de montagens paralelas, para marcar ações centrais e secundárias, insere flashbacks inexistentes na peça, aplica mudanças rápidas de ângulos da câmera, utiliza lentes anamórficas, com efeitos de distorção, experimenta com a dupla exposição e dinamiza ainda mais a corrida frenética do caixa, com tomadas curtas que frequentemente terminam de forma agressiva e abrupta. O diretor não usa a técnica do fade-in e fade-out, muito popular na época, para criar uma sequencialidade harmônica; em vez disso, as rápidas e cruas alterações de tomadas dão ao filme um ritmo duro, brutal e pulsante. Nesse sentido, $D a$ aurora à meia-noite explora bem mais as possibilidades fílmicas do que, por exemplo, O Gabinete do Dr. Caligari com sua técnica estática.

Paralelamente, o filme de Martin reforça uma unidade interna ao mostrar sempre o mesmo relógio, indicando o decorrer do tempo da manhã à meia noite, conforme o título, sem que, portanto, esse motivo ocupe um lugar destacado no filme, por exemplo, via close-up. Também as figuras femininas centrais, a dama, a filha, uma visão, uma prostituta e a mulher do exército da salvação são representadas pela mesma atriz, Roma Bahn, apontando, assim, para a percepção do caixa que anseia por todas essas mulheres. Muitas dessas se transformam, na visão do protagonista, em máscaras de morte, tecnicamente realizado no filme através de dupla exposição. No entanto, dois elementos marcam o filme Da aurora à meia-noite e o diferenciam de seus pares, como Caligari ou Genuine. Em primeiro lugar, na comparação com todos os filmes da época chamados 
Korfmann, M. - Da aurora à meia-noite

de expressionistas no sentido mais amplo, trata-se do único que aproxima uma fonte literária expressionista contemporânea de sua época com uma estética visual que segue claramente a mesma linha estética. Não se situa no mundo das sombras; renuncia ao irracional e obscuro fantasmagórico, como acontece em Caligari, O Golem, ou Nosferatu, em favor do contexto social num ambiente urbano do início do século XX: uma história de dinheiro, sedução erótica, fantasias escapistas, vida boêmia excêntrica, crime e alteração rápida de cenas.

O segundo diferencial é a consequente configuração bidimensional do filme, sua visualidade gráfica em preto em branco que se forma através das linhas brancas e distorcidas, uma rede entre os cenários e as figuras, tornando-os "uma parte do pensamento decorativo" (KURTZ 2007: 69). Nessa qualidade, o filme opõe-se constantemente à ilusão tridimensional e mesmo os efeitos da iluminação não são utilizados aqui para criar espaços de luz e sombra, mas apenas para intensificar, mais ainda, as linhas brancas e seus contornos aplanados. Como exceção, pode-se apontar para a cena do encontro do caixa com a morte no meio de uma paisagem de neve, acompanhado de um longo monólogo. Nessa cena da incorporação da morte, como antecipação dos futuros eventos, surge uma leve tridimensionalidade visual.

Como vimos através da análise da própria peça, a cena acima mencionada pode ser considerada a passagem-chave da peça e possivelmente por isso ganhou um visual diferenciado, já que falta no filme mudo todo o extenso discurso do protagonista. Heinrich de FRIES considerou o espaço bidimensional de Da aurora à meia-noite como contraponto conceitual ao $O$ Gabinete do Dr. Caligari, uma "abstração de caráter passivo, mudo, anorgânico e não sensorial, consequente e radical em seu absolutismo" (1920/21: 63). Dominam nele formas estáticas, linhas simples, um fundo puramente achatado, literalmente "traçando" ambientes, estados de consciência e relações sociais numa rede visual que se inclina para a abstração gráfica, em nome de uma validade mais ampla e geral da condição humana e social. Talvez nessa frieza e rigidez de um mundo de estruturas não penetráveis, no qual os protagonistas agem quase como elementos de formas e sem poder recorrer ao recurso da linguagem para soprar nelas respiração e aspiração, encontre-se uma das razões por que o filme não alcançou uma ressonância 
Korfmann, M. - Da aurora à meia-noite

maior na época, ao passo que a peça se consolidou como o maior sucesso do teatro expressionista.

\section{Conclusão}

Se olharmos para Da aurora à meia-noite no contexto intermedial, a "iluminação recíproca entre as artes” (WALZEL 1917), podemos constatar primeiramente, em nível biográfico, uma forte tendência a transgredir os diversos campos artísticos: Karl Heinz Martin, por exemplo, não apenas dirigiu e encenou peças teatrais, como ainda trabalhou paralelamente na direção de dois filmes nos quais atuaram também seu cenarista Neppach, ele próprio fortemente influenciado pela arte gráfica expressionista, bem como atores vindos da área teatral, como Ernst Deutsch ou Erna Morena. Tais interfaces eram praxe em muitas obras do novo medium fílmico, de tendências artísticas diversas, e se explicam, em boa parte, pela tentativa de consolidar o cinema como nova forma expressiva na cultura da época, recrutando representantes destacados do velho medium da literatura ou do teatro para ganhar credibilidade. Mas esses casos de transferências profissionais e inspirações pontuais se diferenciam, em nossa perspectiva, da proposta de criar um Gesamtkunstwerk em que vida, arte, convicções ideológicas e estéticas se confundem numa obra total, como intencionava parte da chamada vanguarda no início do século XX, sobretudo no movimento Dada ou no surrealismo.

Como mostramos, nem o próprio Georg Kaiser mostrou-se, inicialmente, muito disposto a colaborar na transposição de sua peça para o cinema e sempre se via exclusivamente na tradição textual da dramaturgia. Assim, o caráter fílmico muitas vezes aclamado (KAUL 1960; KASTEN 1990: 52-53; WALK 2007: 180; KÖHLER 2010: 174) da própria peça, escrita entre 1912 e 1915, não pode ser deduzido a partir de uma intenção autoral, mas apenas segundo uma observação dos dois media em questão, o teatro e o cinema. Ao assistir um dos filmes destacados da época, O estudante de Praga de 1913, considerado por muitos críticos como o início do cinema "sério" ou artístico (cf. Korfmann/KePler 2008), nota-se que o drama de Kaiser oferece, com suas 
Korfmann, M. - Da aurora à meia-noite

rápidas alterações discursivas e locais, uma dinâmica muito mais acelerada e diversificada do que os filmes narrativos da época. E a tentativa de Walk de detectar semelhanças entre os Nummernprogramme do início do cinema, a mistura aleatória de curtos trechos de temáticas variadas, e a peça de Kaiser, bem como a comparação de $D a$ aurora à meia-noite com uma colagem no estilo de um fait divers dos jornais (cf. SCHÜRER 1975: 88), não convence, pois exclui por completo todos os elementos temáticos, simbólicos, visuais e narrativos que formam e configuram as sete estações do drama numa unidade interrelacionada porém diversificada.

A versão cinematográfica, por outro lado, objetiva ir além de uma mera filmagem da encenação teatral. Mencionamos, nesse sentido, técnicas como a montagem paralela, a inserção de flash-backs, diferentes ângulos da câmera, a utilização de lentes anamórficas, as tomadas curtas, agressivas e abruptas, bem como a constante bidimensionalidade visual. Com isso, acrescentam-se elementos novos à discussão sobre o chamado cinema expressionista e suas fontes literárias. Lembramos aqui a tradicional generalização do conceito "expressionista" para filmes e suas bases literárias tão diversas, como: O Golem como veio ao mundo (1920), de Paul WEGENER (uma lenda judaica), Dr. Mabuse (1921/22), de Fritz LANG (romance do escritor luxemburguês Norbert Jacques), Nosferatu (1922), de F.W. Murnau (Dracula do escritor irlandês Bram Stocker), As mãos de Orlac (1924), de Robert WIENE (romance do francês Maurice Renard), ou Metropolis (1927), de Fritz LANG (romance de sua esposa Thea von Harbou). E há teóricos como Horst FRITZ (1994), que veem uma continuidade de certos elementos dessas obras, sobretudo em relação aos efeitos de iluminação no Film Noir americano dos anos 1940 e 50. Tais debates surgem, sobretudo, a partir da publicação de A tela demoníaca de Lotte EISNER de 1952, estendendo a denominação de filme expressionista para todos os filmes "as long as these showed some eccentricity in their set designs and used lightning and camera techniques which distort perspective" (SCHEUNEMANN 2003: 1). Para a autora, independentemente dos méritos inegáveis de seu estudo, bastavam poucos elementos fílmicos para classificar um filme como expressionista, ampliando, assim, essa denominação para quase toda produção do cinema de Weimar. 
Korfmann, M. - Da aurora à meia-noite

Também contribuiu para uma homogeneização pouco diferenciada a análise de Siegfried KRACAUER, De Caligari a Hitler, de 1947, sugerindo uma ligação direta entre filmes como o expressionista $O$ Gabinete do Dr. Caligari, a mentalidade alemã dos anos 1920 e a ascensão nazista. KRACAUER argumentou que o medium filme funcionaria como o sismógrafo psicológico de uma sociedade, transportando medos, neuroses, sentimentos e ideologias. "Os filmes de uma nação refletem, de forma mais direta, seu estado histórico do que outros media artísticos" (1979: 53). Tanto Kracauer como Eisner veem o romantismo literário como fonte para motivos centrais dos filmes em questão. KRACAUER constata que o "cinema expressionista com seu mundo povoado por fantasmagorias e figuras bizarras, utiliza, preferencialmente, motivos de velhas lendas e sagas" (1979: 579) e EISNER traça, em A tela demoníaca, as relações dos filmes com obras de autores como Jean Paul, Adalbert Von Chamisso, Ludwig Tieck e, sobretudo, E. T. A. Hoffmann. Entretanto, ambos os críticos, em vez de diferenciarem entre motivos, cenário, iluminação, direção de atores e elementos cinematográficos (como montagem, corte ou movimento da câmera), esforçam-se para interligar o romantismo literário ao expressionismo fílmico por conceitos como: subjetividade potencializada, êxtase e uma atitude antirracional, contribuindo assim decisivamente para a já citada generalização fílmica.

Mesmo com a redefinição em 1958 e 1978 da própria EISNER referente à sua ampla concepção expressionista, as pesquisas sobre o cinema expressionista, por exemplo, de John BARLow (1982) a Francis Courtade (1984), têm a tendência de ampliar o campo do cinema expressionista em vez de tentar defini-lo e, consequentemente, restringi-lo com critérios mais específicos. Somente a partir de Barry SALT (1979) e as publicações posteriores de Jürgen KASTEN (1990), Werner SUdENDORF (1993), Thomas ElSAESSER (1990, 1996, 2000) e Dietrich SCHEUNEMANN (2003), inicia-se uma diferenciação convincente que não se baseia apenas na iluminação excepcional de muitos filmes da época, mas leva em conta fatores como a abstração da mimética do real em favor da criação de uma visão do mesmo, em formas visuais reduzidas, excessivas ou distorcidas, na busca pela essência atrás das aparências. Assim, de forma mais restrita, forma-se o núcleo do cinema expressionista com apenas poucas películas, deixando de fora obras desaparecidas como A Casa na Lua (Karl Heinz 
Korfmann, M. - Da aurora à meia-noite

Martin 1921). Além do consolidado O Gabinete do Dr. Caligari (Robert WIEnE 1920), podemos enquadrar nesse rol Genuine (Robert WIENE 1920), Da aurora à meianoite (Karl Heinz MARTIN 1920) e Raskolnikow (Robert WIENE 1923), bem como o terceiro episódio de O Gabinete das Figuras de Cera (Paul LENI 1924).

Convém, ainda, diferenciar esse grupo internamente: a narrativa com o motivo do Doppelgänger de Dr. Caligari insere-se na tradição romântica, "an offspring of a gothic tale, a late descendent of those split personalities of nineteenth-century Romantic literature who are haunted by their shadows and alter egos" (SCHEUNEMANN 2003: 130), e surpreendeu exclusivamente por sua visualidade inovadora, como já constatou a crítica da época. "A fábula é comum e sente-se sua origem em E.T.A. Hoffmann e Poe. O manuscrito não contém nada, mas nada mesmo de extraordinário. Mas [...] a invenção dos cenários criou a realidade fílmica dos caracteres de Caligari, um mundo diferente do mundo dos outros" (DIE NEUE SCHAUbÜHNE 1920). Podemos estender tal avaliação para o terceiro episódio de $O$ Gabinete das Figuras de Cera, em que a perseguição do casal pelo assassino Jack the Ripper se passa em cenários deformados e tortos, bem como em Genuine, feito "com a intenção de ter o mesmo sucesso de seu modelo Caligari" (BERLINER BÖRSEN-COURIER 1920). Em Genuine, trata-se de uma femme fatale matadora de homens e com boa dose de um erotismo mórbido em voga, "entre desejo e loucura que caracteriza boa parte da literatura moderna" (DER FILM 1920: 28), como escreveu um crítico da época, referindo-se a escritores muito populares na época como Hanns Heinz EwERS.

Se os exemplos citados anteriormente caracterizam-se por uma visualidade expressionista ao redor de narrativas literárias de outras vertentes, o filme Raskolnikow (1923), baseado no romance Crime e Castigo de Fiódor DostolÉvski, de 1866, com cenários também construídos a partir da pintura expressionista, pode ser considerado uma obra de transição, já que a mudança radical do protagonista, no final do romance, pode ser comparada "ao pathos do 'novo homem' do expressionismo" (KASTEN 1990: 80). O escritor russo é considerado como um dos precursores intelectuais do expressionismo literário e suas extremas posições mentais subjetivas, febris e nervosas "pareciam aos escritores expressionistas como parábola da existência do homem moderno" (SCHAROW 1922). Devido à importância da arquitetura para o diretor Robert 
Korfmann, M. - Da aurora à meia-noite

Wiene, já visto em Dr. Caligari e Genuine, este contratou, como cenarista, o russo Andrej Andrejew, que trabalhava para o Teatro Artístico em Moscou e também já tinha construído cenários para o Deutsche Theater de Max Reinhardt em Berlim. A crítica da época viu o filme na tradição do Dr. Caligari e avaliou que o "cenário torto, distorcido, irreal, fantástico, foi provavelmente construído para espelhar os estados mentais de Raskolnikow" (VORWÄRTS 1923).

Os filmes apresentados anteriormente destacam-se por inserir diversas fontes literárias em um ambiente visual expressionista caracterizado por objetos, casas, ruas e interiores deformados, tortos, distorcidos, mas mesmo assim ainda reconhecíveis; eles formam uma arquitetura plástica, com efeitos tridimensionais, usam cores pintadas nos cenários a fim de obter diferenciações de cinza na película preto e branco ou a coloração posterior e tentam criar certa ilusão de profundidade. Da aurora à meia-noite, de KarlHeinz MARTiN (1920), é um caso a parte. Como nas outras películas mencionadas, essa produção fílmica também é resultado de uma colaboração entre diretores, cenaristas e atores vindos do teatro, mas trata-se do único filme que aproxima uma fonte literária expressionista contemporânea de sua época, com uma estética visual que claramente se coloca na mesma linha. Esse filme não se situa no mundo das sombras; renuncia ao irracional e obscuro fantasmagórico em favor de um contexto social do início do século XX, num ambiente urbano: uma história de dinheiro, sedução erótica, fantasias escapistas, vida boêmia excêntrica, crime e alteração rápida de cenas. A película apresenta-se nas cores fundamentais de preto e branco; prevalecem formas estáticas, linhas simples, um fundo puramente bidimensional, que aponta, de maneira muito reduzida, para estruturas do mundo externo, literalmente "traçando" relações lineares de diferentes estados de consciência, que se inclinam, assim, para a abstração gráfica. Nessa película, não se trabalha com efeitos de iluminação no sentido de criar um mundo de sombras e duplicidade, mas somente com linhas brancas distorcidas e quase fosforescentes sobre um fundo preto e, desse modo, aproxima-se das gravuras expressionistas. O filme configura-se através dos cenários reduzidos e parcos de forte teor gráfico, encurtando, concentrando e comprimindo características essenciais do drama textual em formas visuais. Diferencia-se, em termos mediais, da encenação teatral por meio de técnicas como a montagem paralela, a inserção de flash-backs, 
Korfmann, M. - Da aurora à meia-noite

diferentes ângulos da câmera, a utilização de lentes anamórficas, as tomadas curtas, agressivas e abruptas. Assim, o veredito de Siegfried KrACAUER, de 1939, de que "as decorações expressionistas [nos respectivos filmes] são imagens artificiais, carregadas de significado que exigem ser vistas como tais", e que "o dever da câmera se esgota em fotografá-las” é apenas parcialmente aceitável em relação a Da aurora à meia-noite que, sem dúvida, constitui-se a partir da experiência teatral estilizada e ultrapassa paralelamente essa experiência ao desenvolver uma transposição fílmica com uma linguagem cinematográfica dinâmica e bem elaborada para sua época.

\section{Referências bibliográficas}

AnZ,Thomas. Der Sturm ist da. Die Modernität des literarischen Expressionismus. In: Grimminger, Rolf, StÜCKRATH, Jörn e Murasov, Jurij (Hg.) Literarische Moderne. Europäische Literatur im 19. und 20. Jahrhundert. Reinbek bei Hamburg: Rowohlt 1995, p. 257-283.

BALL, Hugo. Flucht aus der Zeit. In: BALME, Christopher. Das Theater von Morgen, Texte zur deutschen Theaterreform (1870-1920). Würzburg: Königshausen + Neumann, 1988, p. 248-255.

BARLOw, John D. German Expressionist Film. Boston: Twayne Publishers, 1982.

BeIL, Ralf/Dillmann, Claudia (Hg.). Gesamtkunstwerk Expressionismus. Ostfildern: Cantz Verlag 2010.

BERLINER BÖRSEN-COURIER. 5.de setembro de 1920.

BERLINER TAGEBLATT, 1 de fevereiro de 1919.

BZ AM MitTAG. 1 de outubro de 1919.

COURTADE, Francis. Cinéma Expressionniste. Paris: Henri Veyrier 1984

DEGENHARDT, Inge. Über Von morgens bis mitternachts. Disponível em: http://www.editionfilmmuseum.com/product_info.php/info/p110_Vonmorgens-bis-mitternachts.html, acesso em 23 de fevereiro de 2010.

DER FILM. 36/1920

DiE NeUE SchaubÜHNE. Monatshefte für Bühne, Drama und Film. Dresden 1920.

DIEBOLD, Bernhard. Anarchie im Drama. Kritik und Darstellung der modernen Dramatik. Frankfurt/Main: Frankfurter Verlags-Anstalten, 1921.

Dillmann, Claudia. Sie hatten das Kino - Die Netzwerke im expresionistischen Film der frühen Weimarer Republik. In: BeIL, Ralf/ DillmanN, Claudia (Hg.). Gesamtkunstwerk Expressionismus. Cantz Verlag: Ostfildern 2010, p. 276-287.

EDSCHMID, Kasimir. Expressionismus in der Dichtung. In: ANZ, Thomas/STARK, Michael (Hg.). Expressionismus. Manifeste, und Dokumente zur deutschen Literatur. Stuttgart: Metzler 1982, p. 42-54.

EISNER, Lotte H. L'écran démoniaque: influence de Max Reinhardt et de l'expressionnisme. Paris: André Bonne 1958. 
Korfmann, M. - Da aurora à meia-noite

ElSAESSER, Thomas (ed.). Early Cinema. London: BFI 1990.

ELSAESSER, Thomas. Weimar Cinema and After. Germany's Historical Imagination. London, New York: Routledge 2000.

ElsAesser, Thomas e Wedel, Michael. A Second Life: German Cinema's first decades. Amsterdam: Amsterdam UP 1996

FILM-KURIER. 4.Jg., Nr.31, 4. de fevereiro de 1922.

FRIES, Heinrich de. Raumgestaltung im Film. In: Wasmuths Monatshefte für Baukunst. 5, 3/4 1920/21, p. 63-82.

FRITZ, Horts. Ästhetik des Films im Kontext von Expressionismus und Neuer Sachlichkeit. In: MenNeMEYeR, Franz Norbert/Fischer-Lichte, Erika (Hg.). Drama und Theater der europäischen Avant-Garde. Tübingen: Francke 1994, p. 387-410.

HAMBURGER ECHO. 1 de outubro de 1918.

HAMBURGER NACHRICHTEN. 30 de setembro de 1918.

HASENCLEVER, Walter. Das Theater von morgen. In: BALME, Christopher (Hg.). Das Theater von Morgen, Texte zur deutschen Theaterreform (1870-1920). Würzburg: Königshausen \& Neumann 1988.

HERALD, Heinz. Notiz zur "Bettler"-Aufführung. In: Das junge Deutschland. Monatsschrift für Literatur und Theater, 1, 1, 1918, p. 30.

HILlER, Kurt. Epressionismus. In: AnZ, Thomas/STARK, Michael (Hg.). Expressionismus. Manifeste, und Dokumente zur deutschen Literatur. Stuttgart: Metzler 1982, p. 37.

JACOBS, Monty. Die leere Bühne. In: Die Deutsche Bühne, 1920/1921, p. 302.

JHERING, Herbert. Regisseure und Bühnenmaler. In: Der Kampf ums Theater und andere Streitschriften. Berlin: Henschelverlag Kunst und Gesellschaft 1974.

KAES, Anton (Hg.). Kino-Debatte. Tübingen: Niemayer 1978.

KAFITZ, Dieter. Zwischen Avantgarde und kollektivem Doskurs. Zur Massendarstellung und Lichtmetaphorik in den Dramen Georg Kaisers. In: MENNEMEIER, Franz Norbert/ FISCHER-LICHTE, Erika (Hg.). Drama und Theater der europäischen Avantgarde. Tübingen/Basel 1994, p. 67 - 90.

KAISER, Georg. Da aurora à meia-noite. Revista Contingentia, vol. 5, no. 2, novembro 2010, p. $38-74$.

KAISER, Georg. Entrevista publicada na Literarische Welt, 11 de fevereiro de 1927.

KAISER, Georg. Werke IV. Berlin: Propyläen Verlag 1971.

KASTEN, Jürgen. Der Expressionistische Film. Münster: MAkS 1990.

KASTEN, Jürgen. On Karl Heinz Martin's From Morn to Midnight. In: ScheunEMANN, Dietrich (Hg.). Expressionist Film, New Perspectives. Rochester, NY: Camden House 2003, p. 157-172.

KAUL, Walter. Von morgen bis mitternachts. Kurier, 7 de outubro de 1960.

KERR, Alfred. Die Welt im Drama. Hg. v. HERING, Gerhard F. Köln, Berlin: Kiepenheuer \& Witsch 1964.

KÖHLER, Gerald. Zum Raum wird hier der Schmerz. Das expressionistische Theater als Gesamtkunstwerk. In: BEIL, Ralf/DiLlmanN, Claudia (Hg.). Gesamtkunstwerk Expressionismus. Cantz Verlag: Ostfildern 2010, p. 172-193.

KoKOSCHKA, Oskar. Schriften 1907-1955. Hg. v. WINGLER, Hans Maria. München: Langen 1956.

Korfmann, Michael/ KePLER, Filipe Kegles. Hanns Heinz Ewers e O estudante de Praga. In: Pandaemonium germanicum 12, 2008, p. 45-64. 
Korfmann, M. - Da aurora à meia-noite

KraCAUER, Siegfried. Wiedersehen mit alten Filmen. Basler National-Zeitung. 2 de maio de 1939.

KraCAUER, Siegfried. Von Caligari zu Hitler. Eine psychologische Geschichte des deutschen Films. Fankfurt/Main: Suhrkamp 1979.

KURTZ, Rudolf. Expressionismus und Film. Berlin 1926. Reeditado por: KIENING, Christian/BEIL, Ulrich. Zürich: Chronos 2007.

LICHTBILD-BÜHNE. 20/1920 e 29/1920.

MARTIN, Karl Heinz. Die Bühne und der Expressionismus. In: Neue Hamburger Zeitung, 1918, n. 230.

OKAJIMA, Krichi. In: Lichtbild-Bühne 52/1923, p. 18.

OSTERHELD, Erich. Wie die deutschen Dramatiker Brabaren wurden. In: Die Aktion, 26.2.1913, p. 261-265, reproduzido em: KAES, Anton (Hg.). Kino-Debatte. Tübingen: Niemayer 1978 , p. $96-100$.

RÜHLE, Günter. Theater für die Republik. 1917-1933 im Spiegel der Kritik. Frankfurt am Main: Fischer 1967.

Runge, Erika. Vom Wesen des Epressionismus im Drama und auf der Bühne. Tese de doutorado, Universidade de Munique, 1962.

SALT, Barry. From Caligari to who? Sight and Sound, vol. 48, 1979. p. 119-123.

SCHAROW, Peter. Expressionsimus im Film. In: Filmschau, 1. de agosto de 1922.

SCHEUnEMANN, Dietrich. Expressionist Films. Rochester, NY: Camden House 2003.

SCHIVELBUSCH, Wolfgang. Lichtblicke. Frankfurt am Main: Fischer 2004.

SCHORLIES, Walter-Jürgen. Der Schauspieler, Regisseur, szenische Bühnenbauer und Theaterleiter Karl Heinz Martin. Versuch einer Biographie. Tese de doutorado, Universidade de Colônia 1971.

SCHÜRER, Ernst. Georg Kaiser. Von morgens bis mitternachts. Erläuterungen und. Dokumente. Stuttgart: Reclam 1975.

SCHWITTERS, Kurt. Anna Blume und ich: Die gesammelten Anna Blume-Texte. Hg. v. Ernst SCHWITTERS. Zürich: Arche 1965.

SPRENGEL, Peter. Von der Baukunst zur Wortkunst. Sachlichkeit und Expressionismus im Sturm. In: DVjs. 64 (1990), p. 680-706.

STURM-BÜHNE. 1918, volume 1.

SUDENDORF, Werner. Expressionism and Film: the Testament of Dr. Caligari. In: BEHR, Shulamith (Hg.). Expressionism Reassessed. Manchester: Manchester UP 1993.

Tannenbaum, Herbert. Probleme des Kinodramas. In: Bild und Film (M.Gladbach), Nr. 3/4, 1913/14.

VORWÄRTS. 30 de outubro de 1923.

WAGNER, Ludwig. Der Szeniker Ludwig Sievert. Berlin: Bühnenvolksbundverlag 1926.

WALDEN, Herwarth. Über allen Gipfeln. Die metergrossen Dichter der Gegenwart. In: Der Sturm, 15 (1924), p. 49-69.

WALK, Cynthia. Cross-Media Exchange in Weimar Culture: Von morgens bis mitternachts. In: Monatshefte, vol. 99, no. 2, 2007, p. 177-193.

WALZEL, Oskar. Wechselseitige Erhellung der Künste. Berlin: Reuther und Richard 1917.

Zimmermann, Verena. Das gemalte Drama. Die Vereinigung der Künste im Bühnenbild des deutschen Expressionismus. Tese de doutorado, Universidade de Aachen 1997. 